\title{
Learner success and digital technologies
}

James Brunton ${ }^{1}$ and Mark Brown ${ }^{2}$

1 Dublin City University, Dublin, Ireland. James.brunton@dcu.ie. Corresponding author.

${ }^{2}$ Dublin City University, Dublin, Ireland. Mark.brown@dcu.ie

Important note:

This is a preprint manuscript provided for educational purposes. The final version of this chapter was published as per the citation presented below.

\section{Cite this publication as:}

Brunton J. \& Brown M. (2020) Learner success and digital technologies. In M. Peters (Ed.) Encyclopedia of teacher education. Springer: Singapore. DOI:

https://doi.org/10.1007/978-981-13-1179-6_107-1 


\section{Learner success and digital technologies}

James Brunton ${ }^{1}$ and Mark Brown ${ }^{2}$

${ }^{1}$ Dublin City University, Dublin, Ireland. James.brunton@dcu.ie. Corresponding author.

${ }^{2}$ Dublin City University, Dublin, Ireland. Mark.brown@dcu.ie

\section{Introduction}

This entry examines the role digital technologies play in learner success, both as a factor that impacts on learner success and in the context of digital technology's role in institutional initiatives and supports designed to enhance learner success. The common goal of learners and educational institutions is that a learner will achieve their educational goals within that institution. When a learner withdraws from the institution this represents a loss of opportunity for that individual to achieve those goals, a loss to the institution in terms of mission and income, as well as a loss to society with regard to the benefits that accrue from an educated populace. Where students do not exit the institution, but progress through a programme without achieving the success of which they are capable, this also represents a loss of potential for the individual, the institution, and society. Learner success is impacted by both learner characteristics and institutional structures and processes. Institutions can enhance learner success through strategic initiatives and the targeted deployment of effective learner supports (Thomas, Hill, O'Mahony, \& Yorke, 2017). In most cases such initiatives and supports are mediated through digital technologies, as their use now permeates most forms of teaching and learning activity.

\section{The fundamentals of learner success}

Defining learner success is a difficult proposition as the term is complex with regard to how we measure and understand it. Learner success is a more learner-centred and positive term than related terms that are deficit-oriented, such as dropout, withdrawal, attrition, failure, or wastage. The term learner success allows for a more holistic view of successful outcomes for a learner than terms such as retention, progression, and completion, which focus on progress within a predetermined time frame in a particular institution. The most tangible, and dominant, measure of success is to calculate retention, progression, and graduation rates. However, non-completion does not necessarily equate to being unsuccessful as withdrawal can be seen as a successful outcome if it is the right choice for that learner. A distinction may be made between a thoughtful withdrawal and academic failure. Learner success can be defined narrowly as completion of a programme of study, or more broadly based on both institutional and learner-as-stakeholder perspectives, incorporating dimensions beyond academic achievement such as behavioural engagement and affective response to study (Picton, Kahu and Nelson, 2018). 
There is broad agreement in the literature on the main factors impacting learner success. These factors are seen as stemming from personal characteristics and institutional structures and processes, as well as the complex interaction between the two. Key, interrelated factors that have been identified can be summarised as: personal characteristics and circumstances; belonging and identification; expectations; academic preparedness; personal organisation and time management; support networks; and the learner experience (see table 1). Learner success is particularly negatively impacted where a combination of factors cause difficulties for a learner.

Table 1 Factors impacting learner success

\begin{tabular}{|l|l|}
\hline $\begin{array}{l}\text { Factors impacting on } \\
\text { Learner Success }\end{array}$ & Description \\
\hline $\begin{array}{l}\text { Personal characteristics } \\
\text { and circumstances }\end{array}$ & $\begin{array}{l}\text { A learner's finances, socioeconomic background, and other } \\
\text { personal characteristics and circumstances (their overall } \\
\text { 'lifeload') can facilitate or become a barrier to success }\end{array}$ \\
\hline Belonging and identification & $\begin{array}{l}\text { A strong sense of belonging in, and identification with, the } \\
\text { institution has a positive effect on success, and on not } \\
\text { exiting the institution during difficult times. Belonging can } \\
\text { relate to the institution itself, learner engagement in their } \\
\text { studies, and/or the degree to which a learner feels socially } \\
\text { integrated. }\end{array}$ \\
\hline Expectations & $\begin{array}{l}\text { Realistic expectations facilitate transition into an institution, } \\
\text { and avoid the "shock" of finding that the educational } \\
\text { experience does not match up with expectations, which can } \\
\text { result in early exit from the institution. }\end{array}$ \\
\hline Academic preparedness & $\begin{array}{l}\text { Previous experience with, or active preparation for, } \\
\text { academic study aids in having realistic expectations about } \\
\text { the learner experience and reduces the risk of academic } \\
\text { failure. This extends to a learner's self-efficacy, their beliefs } \\
\text { in their ability to engage in learning. }\end{array}$ \\
\hline Support networks & $\begin{array}{l}\text { Learners need to be reasonably organised and manage } \\
\text { their time in order to succeed. This is crucial for learners } \\
\text { who combine studying with other time-consuming } \\
\text { commitments. Clashing life-parts can weigh heavily on } \\
\text { learners, and is frequently identified as a reason for exiting. }\end{array}$ \\
\hline time management & $\begin{array}{l}\text { Having a network of supports, both broadly from family, } \\
\text { friends, employers, etc., and within the institution from } \\
\text { peers and staff, will aid learners in overcoming difficulties. } \\
\text { Institutional supports can be informal or formally organised. }\end{array}$ \\
\hline $\begin{array}{l}\text { A satisfactory institutional experience will facilitate learner } \\
\text { engagement and academic progress. As this is based on }\end{array}$ \\
\hline anganer experience
\end{tabular}




\begin{tabular}{|l|l|}
\hline & $\begin{array}{l}\text { learner perceptions of quality it may also relate to } \\
\text { learner-course/institution match, as a learner may not see } \\
\text { value in a course when they have decided it is not the } \\
\text { course for them. Absence of a match can negatively impact } \\
\text { on a sense of belonging. }\end{array}$ \\
\hline
\end{tabular}

Institutions can do much to organise their own structures and processes to facilitate learner success, and can also influence the degree to which a learner's personal characteristics impact on success. This highlights the importance of having strong senior-level institutional backing for a strategic approach to learner success. Initiatives, as is the case with best-practice learner supports and teaching and learning activity generally, should be carefully and coherently developed using established design principles. Given the increased convergence of study modes, for example on-campus, blended, and online study, such initiatives must be designed to accommodate all study modes. While many institutions are engaged in strategic facilitation of learner success, for examples see Thomas et al. (2017), in many instances the culture of leaving learners to 'sink or swim', perhaps following an initial on-entry orientation, remains.

While learner success is bound up with all stages of the study life-cycle, the transition into an institution and the first academic year are crucial. Becoming a learner is an intense and challenging experience as the individual adjusts to the new setting, which is often perceived as alien, and incorporates it into their existing lifeload. Learners are most likely to withdraw in their first year, highlighting the importance of the transition period, which is a phased process that incorporates the pre-entry and on-entry period, and the first year.

Types of initiatives utilised to facilitate learner success are, in broad terms:

- Provision of realistic information about the institution, course, and learner experience in marketing material etc. to facilitate realistic expectations and good learner-institution/programme fit;

- Provision of tools and resources for learners in the pre-orientation period to self-assess their readiness for study;

- Organise facilitated, pre-orientation activities or programmes focused on readiness for study and making a smooth transition into the institution;

- Provision of on-entry, orientation information and supports to combat the 'shock' of unmet, unrealistic expectations and establish realistic ones, reduce anxiety, and aid learners in organising themselves for academic study;

- Socialisation opportunities with peers and/or existing learners to reduce anxiety, offer opportunities to form support networks, and promote a sense of belonging;

- Encourage good rapport with academic staff;

- Identify 'at-risk' learners and employ targeted supports for those learners;

- Design high-quality learning experiences to provide a satisfactory academic experience. 


\section{The role digital technologies play in learner}

\section{success}

Digital Technology is an umbrella term that refers to the contemporary use of technology such as: computing devices such as laptops and smartphones; electronic devices such as digital camera and wearable technologies; technologies that can display digital data, such as smart boards; artificial intelligence systems and tools; systems software, applications software, simulation software, for example, virtual reality; and tools and techniques for data processing, such as those used for data analytics. In many ways digital technologies are integrated into daily life, and a defining feature of these technologies is that they are increasingly social, as seen in the ubiquity of social media activity. The use of digital technologies is generally perceived as giving greater control and flexibility to users, and are seen as enhancing and improving how associated tasks can be accomplished. Within education there is a general, rarely questioned view that an increased use of digital technologies will be beneficial for education and learners. The contested nature of claims made about the role of technology in education should be recognised, and the benefits attributed to digital technologies should not be accepted unquestioningly as these are often based more on "value-driven aspirations" than on empirical evidence (Selwyn, 2017, p.34). The implementation of any digital technology in education must take account of its sociocultural context in order to offer a truly improved or alternative way of tackling central educational issues or functions. Adoption of a digital technology in education often requires a challenging cultural shift in order to be successful (Weller, 2018).

For learners, digital technologies are both something that they need to be able to use in order to be successful in their studies, and are bound up with how the institution provides learner success supports. There is a tension between these two realities. Digital technologies can be both a barrier to and a facilitator of learner success depending on factors such as access to digital technologies, the degree to which learners have associated digital literacies, the quality of provided technologies, the digital literacies and practices of academic staff, and the related supports offered by the institution. Particular categories of nontraditional learners may have less access to digital technologies, which makes it more difficult and time-consuming to study, when these learners often have more pressures on their time.

Keeping in mind the contextual information presented above, digital technologies can be used to facilitate learner success in a number of ways within the broadly stated initiative types described above, and in different phases of a learner's educational journey.

In the pre-entry period digital technologies can be used to provide realistic information in online content describing the programme and the learner experience in that institution. Current or past learners' voices may be used in blogs, videos, or banks of "tips" given to new and prospective learners as well as formal, institutional information that is accurate and understandable. Learners can be supported in preparing themselves through the provision of digital readiness tools focused on key learner success factors, for example self-assessment 
tools for time-management or computer skills, or tools for mapping out their study plan. Ideally, such tools would be used within a cohesive, pre-entry course. Such tools or courses may be closed, only offered to new learners within the 'digital walls' of the institution or open, offered freely through the institution's website or in Massive Open Online Courses (MOOCs) (Brunton, Brown, Costello, \& Farrell, 2018).

If all study modes are to be facilitated, there is a necessity for digital technologies to play a role in on-entry orientation. For online learners orientation must be delivered through digital technologies such as online information sources, resources, readiness tools, or a comprehensive orientation on the institution's website or within the learning management system (LMS)/virtual learning environment (VLE). For on-campus learners, orientation can be underpinned by digital technologies that compliment on-campus activities. If an orientation is developed using digital technologies in the first instance it will better suit learners in all study modes, and can then be adapted for different cohorts.

As learners become registered users of institutional systems these can be used to identify 'at-risk' learners through the use of learning analytics, where data on learners and the contexts in which they study are used to better understand learners and their learning and then improve learning through targeted interventions. Possibly combined with learners' demographic data gathered during the application and registration processes, information from learner activity in the LMS/VLE and other systems can be used to identify learners whose online profiles indicate that they are not likely to succeed. Information can be fed through to the programme team and/or learner support services, often through online dashboards or perhaps using intelligent digital assistants, so that identified students can be offered targeted supports. The information can also be fed back to the learner themselves, possibly as part of an early-alert system such that they can manage their own learning using self-service tools. This allows for more targeted, individualised learner success supports, in comparison to simply advertising or providing supports to all learners regardless of individual needs.

The quality of learning architecture, the design and provision of learning experiences, has a significant impact on learner success across all phases of their educational journey, and digital technologies are now an integral part of that learner experience. In relation to those technologies that learners find most useful in their learning it is important to note the reality of technology use rather than their potential for education as often discussed in the literature (Henderson, Selwyn, \& Aston, 2017). Reports based on large scale surveys of students, for example the JISC Digital Tracker or the ECAR Study of Undergraduate Student and Information Technology, give us insights into the lived experience of learners digital technology use. Learners use digital technologies, both those personal to them such as their own digital devices, and those provided by the institution such as online calendars and LMS/VLE tools, to tackle the logistics of organising their studies and completing required work, for example by writing up assignments in digital documents. Learners also use digital technologies in more complex, learning-related tasks such as: revisiting learning materials available to them digitally; communicating and collaborating using social media, cloud-based collaborative files, wikis, etc.; and researching information needed to study and complete academic work using resources from inside and outside the institution. The way in which 
learners use digital technologies within a particular institution is influenced by that institution's strategic approach, or lack thereof, to the use of digital technologies for teaching and learning. Where an institution does not have a strong approach to the use of digital technologies for complex learning practices, then the ways in which digital technologies will be used to support learner success will be more limited and focused on more strategic and surface aspects of learning. (Henderson, Selwyn, \& Aston, 2017).

The way in which an institution's learner support services utilise digital technologies to support learner success is also important, especially in the context of supporting all study modes and in recognising that learners often need help in the evenings or at weekends when traditional, campus-based services are not available to them. Learner support services can provide online information and resources that can be accessed at any time and/or deploy supports that use artificial intelligence (AI) systems such as intelligent databases or 'chatbots' that can help learners find the information they need or the solution to their problem. These systems can be combined with learning analytics to provide tailored, personalised supports. Learner support services may also choose to 'unbundle' some supports by contracting external companies to provide out-of-hours digital services such as online academic writing supports or psychological counselling.

Some of the emerging trends referenced above, for example those utilising Al or personalised and adaptive learning, have yet to be comprehensively researched. Further investigation is required into what roles such digital technologies are playing in learners' institutional experiences, what meaning is being ascribed to that technology use, and what intended and unintended impacts these digital technologies are having on learning, and learner success.

\section{Summary}

While the key factors impacting on learner success are well established: personal characteristics and circumstances; belonging and identification; expectations; academic preparedness; personal organisation and time management; support networks; and learner experience, the term itself is both complex and ill-defined. Learner success can be narrowly defined by using institutional retention and completion data, or defined broadly to create a more holistic, learner-centred conceptualisation of success. There are many learner success initiative-types utilised by institutions, often focusing on a particular timeframe in learners' educational journeys. While all parts of that journey are important, the pre-entry, on-entry, and first year periods are particularly important as the transition into education is challenging and learners are most likely to withdraw in their first year.

As digital technologies now permeate the learner experience, learner success initiatives are frequently mediated through technology, and this is a necessity if learners in different study modes are to be accommodated. Digital technologies can impact on learner success through: facilitating transition into the institution using realistic online information and digital readiness tools, courses, etc.; delivering accessible, on-entry digital orientation supports; using learning analytics to identify 'at-risk' learners and provide targeted supports or learning 
solutions; and providing high-quality learning architecture within which learners effectively use digital technologies for logistical and learning-related tasks. Senior-level institutional backing for a strategic approach to both learner success and the role of digital technologies in teaching and learning activities is crucial.

It is necessary to recognise that digital technologies act as both barrier to and facilitator of learner success. Its ubiquity within the educational context challenges those for whom related digital literacies or access to digital technology is an issue. The messy reality within many institutions is that the use of digital technologies is surface and strategic, reflecting the teaching and learning culture. Finally, it is necessary to remember that implementing technology in educational contexts is complex and challenging, and that claims made about the potential impact of digital technologies to support learners must not be accepted unquestioningly. Evidence-based assessments of technologies should be the basis for decision making, and further research is required in this regard.

\section{References}

Brunton, J., Brown, M., Costello, E., \& Farrell, O. (2018). Head start online: flexibility, transitions and student success. Educational Media International, 55(4), 347-360. doi: $10.1080 / 09523987.2018 .1548783$

Henderson, M., Selwyn, N. \& Aston, R. (2017). What works and why? Student perceptions of 'useful' digital technology in university teaching and learning. Studies in Higher Education, 42(8), 1567-1579. DOI: 10.1080/03075079.2015.1007946

Picton, C., Kahu, E. R. \& Nelson, K. (2018). "Hardworking, determined and happy": first-year students' understanding and experience of success. Higher Education Research \& Development, 1-14.

Selwyn, N. (2017). Education and technology: Key issues and debates (2nd edition). London: Bloomsbury Academic.

Thomas, L., Hill, M., O’Mahony, J. \& Yorke, M. (2017). Supporting student success: strategies for institutional change. In Findings and Recommendations from the What Works? Student Retention and Success Programme. London: Paul Hamlyn Foundation

Weller, M. (2018). Twenty years of EdTech. Educause Review, July/August, 35-48. Retrieved from https://er.educause.edu/articles/2018/7/twenty-years-of-edtech 